\title{
Possible Role of 5-Alpha Reductase Inhibitors in Non-Invasive Bladder Urothelial Neoplasm: Multicentre Study
}

Journal: Minerva Urologica e Nefrologica

Paper code: Minerva Urol Nefrol-3563

Submission date: July 6, 2019

Article type: Original article

Files:

1. Reply letter to comments on the manuscript

Version: 1

Description: Answers to reviewers

File format: application/msword

2. Manuscript

Version: 2

Description: Main Textfile Ver. 2

File format: application/msword

3. Figures 1

Version: 1

Description: Figure 1

File format: image/jpeg

4. Figures 2

Version: 1

Description: Figure 2

File format: image/jpeg

5. Figures 3

Version: 1

Description: Figure 3

File format: image/jpeg 


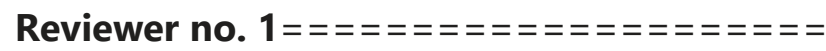

General comment (originality, scientific accuracy, strengths and/or weaknesses): An original work, I think as the first work done in this field, will open up new horizons. length of the article, discussion is sufficient, there may be a lack of material method part, but I ignore it.

Major corrections (main criticisms): I congratulate the authors

Minor corrections (page, paragraph, line where the author must make the corrections): I think it can be published without any changes

Answer: Thanks for your revision and all your compliments about our paper. We hope taht our study might represent the first step to investigate the role of androgens in bladder cancer.

\section{Reviewer no. 2}

$=$ = = = = = = = = = = = = = =

General comment (originality, scientific accuracy, strengths and/or weaknesses): The authors assess the effect of 5-ARIs on the recurrence of NMIBC showing that patients receiving 5-ARIs has lower recurrence rate with lower grade tumors. The main strength of the current study is the scarce data about this topic in the literature and the main weakness is the retrospective nature of the study and the abscence of female patient.

Answer: Thanks for these comments, certainly, we do completer agree with you about the retrospective nature of this study and the absence of femalesubjects. Unfortunately this drug category (5ARIs) is off label, as you surely know, for femares.

Major corrections (main criticisms).

1- Please update the reference list for example Reference number 1 can be updated to the most recent publication "Globar cancer statistics 2018: GLOBOCAN estimates of incidence and mortality worldwide for 36 cancers in 185 countries" published in 2018

Answer: Thanks for this inportantsguggestion, following your advice we add this up-to-date reference for the epidemiologr of bladder cancer.

2- In the discussion, I suggest that authors report the results of similar studies and compare it with their study like "PMID: 27506696", Furthermore, there is a recent published study that showed that Finasteride doesn't prevent bladder cancer it will be interesting if it is added in the discussion "PMID: 29731413"

Answer: Thanks for this important suggestion. The first paper by Shioto et al, was already discussed within the manuscript and the reported data support our results. About the second suggested paper by Sathianathen et al. ("Finasteride does not prevent bladder cancer: A secondary analysis of the Medical Therapy for Prostatic Symptoms Study") the overall incidence of bladder cancer was very limited, resulting in only 18 patients $(0.8 \%)$ The Authors concluded that there was no difference in the incidence of bladder cancer between men who received finasteride and those who did not $(0.74 \%$ vs. $0.61 \%, p=0.67)$. Sincerely, due to the bias of this study (i. e. lack of data on 
potential confounders, for example, smoking history), and to the limited number of patients with bladder cancer we did not added this study in the discussion section.

Minor corrections (page, paragraph, line where the author must make the corrections): Please add table 1 in the study and not as a supplementary material

Answer: As correctly suggested, we add the Table 1 at the end of the manuscript.

$==$ =ニ=ニ= = = = = = = = = =

\section{Reviewer no. 3}

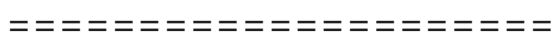

General comment (originality, scientific accuracy, strengths and/or weaknesses). Thank (yoy very much for the opportunity to review your manuscript, of the study about association between 5 alpha reductase inhibitors and bladder cancer. In 2014, Izumi et al first reported 61adoder cancer $(B C)$ recurrences under androgen deprivation therapy (ADT) in prostate cancer $B C$ ) patients were significantly lower than PC without ADT. Thereafter Shista et al reported that not only ADT, but also androgen suppression therapy with 5 -alpha reductase inhibitors regduced $B C$ recurrence. The authors collected as much as 423 BC patients from italian multicenter and drew a similar conclusion to the previous studies. This study is significant in that it dealed previous studies.

Major corrections (main criticisms): You need to do mulivariate analysis to adjust multiple confounding risk factors to evalyate the effect of 5-ainha reductase correctly. Minor corrections (page, paragraph, (ine where the author must make the corrections): None.

Answer: Thanks for your revision. As yolocorrectly suggested, we have updated the manuscript with the univariate and multivariate analysis focusing on the risk of recurrences. We described the multivariate analysis in statistics section and we inserted a second Table (Table 2) containing the analysed data. Thanks again for this important suggestion, which allowed to better support our results.

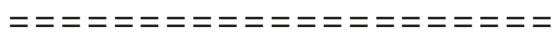

Scheda di revisione editoriale

$===============$

Tabelle: Si prega di spostare la tabella al fondo del file del manoscritto.

Figure: Si prega di specificare le didascalie delle figure inserendole al fondo del file del manoscritto. 


\title{
Possible Role of 5-Alpha Reductase Inhibitors in Non-Invasive Bladder Urothelial Neoplasm: Multicentre Study
}

\author{
Antonio Luigi Pastore ${ }^{{ }^{*}}$, Andrea Fuschi ${ }^{1^{*}}$, Cosimo de Nunzio ${ }^{2}$, Matteo Balzarro ${ }^{3}$, \\ Yazan Al Salhi 1, Gennaro Velotti ', Alessia Martoccia ', Lorenzo Capone', Nelia \\ Amigoni $^{3}$, Mario Falsaperla ${ }^{4}$, Consalvo Mattia ${ }^{5}$, Walter Artibani ${ }^{3}$, Andrea Tubaro ${ }^{2}$, \\ Antonio Carbone ${ }^{1}$
}

1Sapienza University of Rome, Faculty of Pharmacy and Medicine, Department of MedicoSurgical Sciences and Biotechnologies, Urology Unit, Latina; Uroresearch, no profit Association for Research in Urology, Latina, Italy

2Sapienza University of Rome, Department of Urology, Sant'Andrea Hospitai Rome, Italy 3University of Verona, Department of Urology, Azienda Ospedaiiera Universitaria Integrata, Verona, Italy

${ }^{4}$ Vittorio Emanuele Hospital, Department of Lrology, Cataniadtaing

${ }^{5}$ Sapienza University of Rome, Faculty of Pharmacy and Medicine, Department of MedicoSurgical Sciences and Biotechnologies, Anesthesiology Unit, Latina, Italy

Running title: 5 ARIS in NMiBC

*Corresponding Author: Antonio Luigi Pastore, MD, PhD, Assistant Professor, Urology Unit, Department of Medical-Surgical Sciences and Biotechnologies, Faculty of Pharmacy and Medicine, "Sapienza" University of Rome, Latina (LT) Italy

Work Address: Corso deila Repubblica 79, 04100 Latina (LT), Italy

E-mail: antopası@notmail.com, antonioluigi.pastore@uniroma1.it

Tel.: +39 3401138648 ; Fax. +3907736513333

*Both Authors equally contributed to the data collection, draft and revision of the manuscript so they have to be considered as First Author 


\begin{abstract}
BACKGROUND: About $75 \%$ of urothelial bladder cancers are non-muscle invasive (NMIBC), and limited to mucosa (Ta or CIS) or sub-mucosa (T1). An increase of androgen expression and androgen receptors has a positive effect on oncogenic expression. We aimed to evaluate whether 5 -alpha reductase inhibitors (5-ARI) have a role in NMIBC.
\end{abstract}

METHODS: We retrospectively evaluated the clinical and pathologicai data of 423 patients with NMIBC who underwent transurethral bladder resection. We analysed the number of resections, number of total recurrences, time of recurrences, and histopathoiogy details. The population was classified into two groups: treated and untreated with 5-ARIs. The enrolled patients were in treatment with 5ARIs for symptomatic prostatic hyperplasia for at least 12 months. Mean follow-up time was 30.43 months.

RESULTS: Patients treated with 5-ABIs had a lower rate of recurrence (14\%) than the untreated group (37\%). There was a significant difference in the mean number of recurrences between the untreated and the treated group ( $p$ value: 0.006). Furthermore, the treated group showed a significantly greater number of low than high grade tumours, compared to the untreated group ( $p$ value $\leqslant 0.05$ ). There was a significant decrease in the number of muscle invasive tumours in treated patients ( $p$ value $=0.032$ ). The recurrencefree survival rate of patients treated with 5 -ARIs was significantly higher ( $p$ value: 0.0001 ).

CONCLUSIONS: Long-terna treatment with 5- ARIs might reduce the risk of bladder tumour recurrence, extension of lesions and increase the recurrence-free survival rate. A long-term, randomized prospective study could definitively assess the possible role of these drugs.

Keywords: bladder cancer, 5 alpha reductase inhibitors, TURB, NMIBC 


\section{INTRODUCTION}

Bladder cancer (BC) represents the seventh most prevalent malignant disease in the male population in the world, and the eleventh in both genders. In the European Union the agestandardised incidence rate is 19.1 for men and 4.0 for women [1].

It is the thirteenth most common cause of cancer death. The most common $\mathrm{BC}$ type is transitional cell carcinoma, also called urothelial carcinoma. Approximately $75 \%$ of patients with BC present with a disease confined to the mucosa (stage Ta, CIS) or submucosa (stage T1); in younger patients (< 40 y.0.) this percentage is even highen [2]. Patients with Ta, T1 and CIS have a higher prevalence (due to long-term survival in most of cases) and lower risk of cancer-specific mortality when compared to T2-4 tumours [1, 3].

These tumours often recur, and in about $20 \%$ of cases, progress to high grade muscleinvasive $\mathrm{BCa}$ (MIBC), which is more likely to develop metastases [4]. Intravesical recurrence and progression to invasive cancer seems to be iinked to the number of bladder lesions, tumour grade, tumour stage and conicomitant presence of carcinoma in situ (CIS) [5-7]. The common risk factors of urothelial capcer include aging [8], smoking history [9], medications, occupational exposures, water arsenic, Schistosoma haematobium infection, irradiation [10], and genetic factors [11]. Male gender is also a well-known risk factor, supported by evidence nnumerous pre-clinical studies showing the involvement of androgen receptor (AR) signalling in bladder carcinogenesis and bladder cancer growth $[12,13]$. This seems to be confirmed by a decreased incidence of primary bladder cancer after andiogen-dererivation therapy (ADT) compared with surgical therapy and radiotherapy for prostate Caricer [14]. In the male population, the high prevalence of benign prostatic hyperplasia $(\mathrm{BPH})$ with lower urinary tract symptoms, has led, over the years, to a widespread use of $5 \alpha$-Reductase inhibitors (5-ARIs).A reduced incidence of bladder carícer with 5-ARIs has been reported, linked to the catalization of testosterone into dihydrotestosterone, which is 10-fold more potent than testosterone [15]. Similarly, Izumi et al. also reported an inhibitory effect of Androgen-suppression therapy (AST) on the occurrence and recurrence of bladder cancer [16]. Currently, in the literature, a limited number of studies evaluate the effect of 5-ARIs administered for BPH on bladder cancer recurrence. In this retrospective study, we examine the behaviour of non-muscle invasive bladder cancer (NMIBC) in male patients in treatment with or without 5-ARIs. 


\section{MATERIALS AND METHODS}

This retrospective study evaluated 423 patients with previous NMIBC who underwent transurethral resection of bladder (TURB) for the first time between January 2015 and June 2017. Data analysis was performed in December 2018 to achieve at least 18 months of follow up. The study was performed in accordance with the Ethical Principles for Medical Research Involving Human Subjects (World Medical Association, The Declaration of Helsinki Principles, 2000). Data were collected through a careful analysis from the archives of three Urology departments. Of the 423 evaluated patients, we excluded patients with a lack of data regarding personal therapy (51), a lack of histopathological reports (12), those lost during follow-up (38) and those with squamous cellogarcinoma components (10). The study was conducted on 312 patients and the following parameters were considered: age, smoking habits, histopathological data and medan follow-up (Table 1). Regarding patient's medication, particular attention was paid ta use of dutasteride, a 5ARIs approved for BPH treatment. Only patients who underweit TURB for the first time with diagnosis of Urothelial Bladder Cancer ( $\triangle B C$ ) were considered. They were divided in two groups: Group A, (165 patients) including patients that had taken dutasteride $0.5 \mathrm{mg}$, one capsule daily for at least 1 year before TURB) Group B, (147 patients) including patients untreated with 5-ABis. The first risk factor for urothelial bladder cancer, namely smoking habits, was found to be not statisticaily significant between the two groups. The patients were categorized on tobacco-use) hever smokers (106; defined as smoking 0-100 cigarettes in their lifetime), smokers (1)09; smoked more than 100 cigarettes) and former smokers (97: sinoked more than 100 cigarettes but had quit smoking before the time of recruitment). The tollowirg parameters for UBC were considered: age and number of lesions at first cilagnosis, number of lesions in recurrence, number of recurrences and histopathological findings at first resection and in recurrence (Table 1). All surgical specimens were staged according to the TNM classification of the Union Internationale Contre le Cancer (UICC), updated in 2009 [17]; tumour grading was evaluated according to the 2004 World Health Organization (WHO) classification for UBC [18]. All procedures were performed by 3 experienced urologists under spinal/general anaesthesia using a Bipolar Technique with Olympus device and with $0.9 \%$ saline as irrigation fluid. The surgical technique and antimicrobial prophylaxis regimens were left to each surgeon's preference. After the procedure, continuous bladder irrigation was initiated until achieving clear urine output and then discontinued. After the surgical procedures (TURB), adjuvant intravesical Mitomycin C (MMC) or Bacillus Calmette-Guérin (BCG) was administered to 
all patients, following European Association of Urology (EAU) guidelines [18]. The initial instillation generally occurred within 2-4 weeks of the diagnostic TURB and was repeated once weekly for 6 weeks and once monthly for 6 months. No patient received neo-adjuvant therapy, adjuvant systemic chemotherapy, or radiotherapy. The follow-up of the patients, as recommended by EAU guidelines, consisted of urinary cytology, upper urinary tract ultrasound, or computed tomography urography for the first year, and cystoscopy every three months [18]. Patient therapy was evaluated at each medical examination recorded during follow-up, with particular attention to the use of 5-ARIs.

\section{STATISTICAL ANALYSIS}

The statistical analyses were performed using JMP11 software (SA, Institufe, Cary, NC, USA) and SPSS software (version 21.0; SPSS Inc, Chicago, IL). Unit ard multivariate modelling was performed with Fine and Gray subdistribution hazards model. The variables were further analyzed in multivariate competing-risk regression models. Subgroup analyses were exploratory, and no adjustments for multiplicity were made. Subdistribution hazard ratios (SHRs) estimated model were reported as relative risks with corresponding 95\% confidence intervals $(\mathrm{CI})$. Student $\mathrm{t}$-test for paired samples and ANOVA test were performed to compare the results in the same THRB group and to compare the results between the non-treated and treated with 5-Akis groups, respectively. The Kaplan-Meier was used to obtain the curve for recurrence-free survival (RFS). P values $<0.05$ were considered statisticaily significant.

\section{RESULTS}

In this study, as shown in Table 1, we enrolled a total of 312 male patients divided into two study groups: Group A, (165 patients) represented by the patients treated with dutasteride $0.5 \mathrm{mg}$ and group B, (147 patients) untreated with 5-ARIs. The mean follow-up of group A and group B was 31.37 months (SD: 9.22) vs 29.5 months (SD: 9.7; $p$ value: 0.15 ), respectively. Both were statistically homogeneous and comparable regarding age, smoking habits and medication history ( $p$ value $>0.05$ ). The most represented drug, besides Dutasteride, was cardioaspirin but without statistically significant differences between the two groups. Patients mean age at first diagnosis of bladder tumour in group $A$ and group $B$ was 75.23 years (SD: 10.51) and 75.12 (SD: 9.27 , p value: 0.93 ), respectively 
(Table 1). At the time of first resection, between group $A$ and group $B$, the variables evaluated showed: mean number of bladder lesions 1.7 (SD: 1.44) vs 1.92 (SD: 1.68; $p$ value: 0.323); T-category: pTa 40\% vs 35\% - pT1 52.2\% vs 53.7\% - pT2 6\% vs 9\% - pT3 $1.8 \%$ vs $2.3 \%$ ( $p$ values > 0.05); tumour grade: Low Grade 34\% vs 24.8\%; High Grade $66 \%$ vs $75.2 \%$ ( $p$ values > 0.05); presence of CIS was comparable between the two groups (8.7\% vs 10.3\%; p value: 0.083), respectively. Clinical and pathological characteristics are shown in Table 1 and Figure 1. All the patients had undergone bladder instillation with intravesical MMC (129) or BCG (153) in accordance with the EAU guidelines without significant difference of distribution between the two groups. During follow-up, 77 patients, 23 (14\%) from group A and 54 (37\%) from group B ( $p$ value: 0.003), showed at least one recurrence of bladder tumour. About relapsing patients, 90 and 13 patients in group A had undergone MMC and BCG respectively ( $p$ value $>0.05$ ). The same non statistically significant results were obtained in group B with 24 patients treated with MMC and 30 patients with BCG ( $p$ value $>0.05$ ) (Table 1. In particular, recurrent bladder cancer occurred 1.23 times in group A (SD: 0.21) and 1.94 times in group B (SD: 0.14; $p$ value: 0.006) (Table 1, 2, Figure 2). Oi these patients, in group $A$ and in group $B$ we recorded T category and tumour grade, respectively: pTa $35.3 \%$ vs $33.3 \%$ ( $p$ value: 0.072); pT1 57\% vs 50\% (p value: 0.64), pT2 7.7\% vs 16.7\% (p value: 0.041 ); low grade: $47 \%$ vs $35 \%$ ( $p$ value: 0.043 ); high grade: $53 \%$ vs 65\% ( $p$ value: 0.039 ) (Table 1 , Figure 2). The number of tumour lesions between groups $A$ and $B$ at second TURB was not significantly different (mean: 1.13 vs 1.3 , SD: 1.3 vs 1.49 ; $p$ value: 0.750 ). The relation of these variables and the risk of recurrence regardeing the treatment with 5 -ARIs in both groups was confermed in the univariate and multivariate analysis (Table 2). The recurrence-free survival rate of patients treated with 5-ARIs, obtained with Kaplan-Meier curve, was significantly higher compared to patients of group B (SD: $1.07 ; p$ value: 0.0001 - log rank test) (Figure 3). In accordance with the EAU guidelines, radical cystectomy was performed on 13 patients from group A (7.8\%; SD: 0.27 ) and 26 patients from group $B$ (17.5\%; SD: 0.38; p value: 0.032) (Table 1).

\section{DISCUSSION}

There are few studies in the literature concerning the effects of the 5-ARI use in urinary bladder urothelial cancer. This tumour is also known to be more common in men than in women, but the reasons are still relatively unknown $[1,19]$. The rationale behind this study is that androgens, as shown in the literature, could play an important role in regulating the 
urinary bladder urothelial carcinogenesis, which could explain its higher incidence in male patients [20, 21]. To enhance this hypothesis, previously reported epidemiologic studies have shown an increased risk of bladder urothelial cancer in postmenopausal compared to premenopausal women [22]. Despite the small number of studies related to this possible correlation, it seems that there is a potential role of androgens in urothelial bladder cancer. Few previous studies have reported androgen receptor (AR) expression in urinary bladder tumour and all demonstrated AR immunoreactivity in carcinoma cells [20, 21, $23-31$. Moreover, results obtained from experimental studies on animal models suggest the possible stimulatory role of AR mediated intracellular signalling in the development of urinary bladder carcinoma [32].

In literature, there are a growing number of studies that describe the possibie, Correlation between $5 a-r e d u c t a s e$ and urothelial cancer.

A reduced bladder cancer incidence among men taking finasteride, was recently reported in the PLCO study [15]. In line with this notion, our study confirried the possible role of 5ARIs, in particular of dutasteride $0.5 \mathrm{mg}$, that seem to play a prophylactic role in bladder cancer recurrence. Despite the relatively small sample size of our study, we found a significantly lower number of patients yith recurrent bladder disease and a lower median number of bladder lesions at recurrence in our statistically comparable groups. Although a low statistical significance, our data would seen to indicate a possible protective role in differentiation of the tumiour celis, showing a significantly greater number of low tumour grade compared to high grade in patients treated with dutasteride. We also observed a significant decrease in the number of muscle invasive tumours and therefore of radical cystectomies in patients treated with dutasteride.

Furthermore, a significani improvement in the recurrence-free survival between the first TURB and the recurrence was reported, suggesting that 5-ARIs might be really involved in carcinogenesis. These results again are in agreement with data reported in literature [33], that supposed the role of AR signalling to promote DNA breaks and chromosomal rearrangements, leading to the emergence of oncogenic fusion-genes [34, 35]. Along with the involvement of this pathway to a suppression of detoxification through the control of UDP-glucuronosyltransferases [36], AR signalling seems to promote de novo carcinogenesis and bladder cancer recurrence.

As reported in other studies, AR regulates urothelial cell proliferation and the inhibition of this pathway, also with 5-ARls, has been shown to prevent bladder carcinogenesis and tumour cell proliferation [32, 37]. The involvement of the AR signalling in this kind of 
tumour seems to be confirmed by reports of reduced risk of secondary bladder cancer and of the intravesical recurrence in patients with prostate cancer and concomitant NMIBC [14, 16]. In addition, several studies suggest a possible role for AR signalling in migration, invasion, and metastasis of bladder cancer [28, 38].

This study has several limitations such as the relatively non homogeneous small sample size, the absence of female population, and the relatively short follow-up. However, it represents one of the few studies in the literature that analyses and confirms the role of 5ARIs in a widespread disease such as bladder urothelial cancer. In the future, more studies will be needed related to the molecular aspects involved in the AR pathways because it could open new frontiers in the prevention and treatiment of bladder urothelial cancer.

\section{CONCLUSIONS}

This study showed a prophylactic role for 5-APils in bladder cancer recurrence, in particular of dutasteride $0.5 \mathrm{mg}$. The group treated with 5-ARls had a significantly decreased risk of recurrence, a significant improvement of the recurrence-free survival, and fewer numbers of muscle invasive tumours. These encouraging results need to be confirmed by a prospective, randornised controlled study.

Acknowledgements: None

Conflict of interest: Allother abthicrs have no conflicts of interests or financial ties to disclose.

Funding: This research did not receive any specific grant from funding agencies in the public, commercial, or not-for-profit sectors. 


\section{REFERENCES:}

1. Bray F, Ferlay J, Soerjomataram I,et al. Global cancer statistics 2018: GLOBOCAN estimates of incidence and mortality worldwide for 36 cancers in 185 countries. CA Cancer J Clin. 2018;68(6):394-424. doi: 10.3322/caac.21492.

2. Comperat $\mathrm{E}$, Larré $\mathrm{S}$, Roupret $\mathrm{M}$, et al. Clinicopathological characteristics of urothelial bladder cancer in patients less than 40 years old. Virchows Arch, 2015; 466: 589-94.

3. Burger M, Catto JW, Dalbagni G, et al. Epidemiology and risk tactors Ut urothelial bladder cancer. Eur Urol, 2013; 63: 234-41.

4. Sanli O, Dobruch J, Knowles MA, Burger M, Alemozaffar M, Nielsen MIE, et al. Bladder cancer. Nat Rev Dis Primers 2017; 3:17022. 10.1038/nrdp.2017.22.

5. Sylvester RJ, Van Der Meijden AP, Oosterlinck Wy, et ar Bredicting recurrence and progression in individual patients with stage $T a T 1$ bladder cancer using EORTC risk tables: a combined analysis of 2596 patients from seven EORTC trials. Eur Urol 2006; 49: 466-75.

6. Crivelli JJ, Xylinas E, Kluth LA, et al. Effect of smoking on outcomes of urothelial carcinoma: a systematic revies of the literature. Eur Urol 2014; 65: 742-54.

7. Van Lingen $A V$ and Witjes $\backslash A$. Current intravesical therapy for non-muscle invasive bladder cancer. Expert Opin Biol Ther 2013; 13: 1371-85.

8. Shariat SF, Milowsiky M and Droller MJ. Bladder cancer in the elderly. Urol Oncol 2009; 27: $653-67$.

9. Simonis $K$, Shariat $S F$ and Rink M. Smoking and smoking cessation effects on oncological outcomes in nonmuscle invasive bladder cancer. Curr Opin Urol 2014; 24 : 492-9.

10. Bostrom PJ and Soloway MS. Secondary cancer after radiotherapy for prostate cancer: should we be more aware of the risk? Eur Urol 2007; 52: 973-82.

11. Malats $\mathrm{N}$ and Real FX. Epidemiology of bladder cancer. Hematol Oncol Clin North Am 2015; 29: 177-89.

12. Dobruch J, Daneshmand S, Fisch M, et al. Gender and Bladder Cancer: A Collaborative Review of Etiology, Biology, and Outcomes. Eur Urol 2016; 69: 300-10.

13. Li $\mathrm{Y}$, Izumi $\mathrm{K}$ and Miyamoto $\mathrm{H}$. The role of the androgen receptor in the development and progression of bladder cancer. Jpn J Clin Oncol 2012; 42: 569-77. 
14. Shiota M, Yokomizo A, Takeuchi A, et al. Secondary bladder cancer after anticancer therapy for prostate cancer: reduced comorbidity after androgen-deprivation therapy. Oncotarget 2015; 6: 14710-9.

15. Morales EE, Grill S, Svatek RS, et al. Finasteride Reduces Risk of Bladder Cancer in a Large Prospective Screening Study. Eur Urol 2016; 69: 407-10.

16. Izumi $\mathrm{K}$, Taguri M, Miyamoto $\mathrm{H}$, et al. Androgen deprivation therapy prevents bladder cancer recurrence. Oncotarget 2014; 5: 12665-74.

17. Sobin LH, et al. TNM classification of malignant tumors. UICC International Union Against Cancer. 7th edn. 2009, Wiley-Blackwell.

18. Babjuk M, Böhle A, Burger M, et al.EAU Guidelines on Non-Muscle-invasive Urothelial Carcinoma of the Bladder: Update 2016. Eur Urol. 2017;71:447-461.

19. Madeb R, Messing EM. Gender, racial and age differences in bladder cancer incidence and mortality, Urol. Oncol. 2004;22:86-92.

20. Tuygun C, Kankaya D, Imamoglu A, et al. Sex-specific hormone receptors in urothelial carcinomas of the human urinary bladder: a comparative arialysis of clinicopathological features and survival outcomes according to recepior expression, Urol. Oncol. 2011;29:43-51.

21. Boorjian S, Ugras S, Mongan NR, et/al. Angrogen receptor expression is inversely correlated with pathologic tumpr stage in bladider cancer, Urology 2004;64:383-8.

22. McGrath M, Michaud DS, De Vivo 1. Hormonal and reproductive factors and the risk of bladder cancer in woinen, Am. J. Epidemiol. 2006;163:236-44.

23.Zhuang 8 , B Blauer M, Tanmela T, Tuohimaa P. Immunodetection of androgen receptor in human urinary oladder cancer, Histopathology 1997;30:556-62.

24. Boorjian SA, Heemers HV, Frank I, et al. Expression and significance of androgen receptor coactivators in urothelial carcinoma of the bladder, Endocr. Relat. Cancer 2006;16:123-37.

25. Mir C, Shariat SF, Zlotta AR, et al. Loss of androgen receptor expression is not associated with pathological stage, grade, gender or outcome in bladder cancer: a large multi-institutional study, BJU Int 2011;108:24-30.

26. Zheng $\mathrm{Y}$, Izumi $\mathrm{K}$, Yao JL, Miyamoto $\mathrm{H}$. Dihydrotestosterone upregulates the expression of epidermal growth factor receptor and ERBB2 in androgen receptor positive bladder cancer cells, Endocr Relat Cancer 2011;18:451-64. 
27. Miyamoto H, Yao JL, Chaux A, Zheng Y, Hsu I, Izumi K, Chang C, Messing EM, Netto GJ, Yeh S. Expression of androgen and oestrogen receptors and its prognostic significance in urothelial neoplasm of the urinary bladder, BJU Int 2012;109:1716-26.

28. Jing Y, Cui D, Guo W, Jiang J, Jiang B, Lu Y, Zhao W, Wang X, Jiang Q, Han B, Xia S. Activated androgen receptor promotes bladder cancer metastasis via Slug mediated epithelial-mesenchymal transition, Cancer Lett 2014;348:135-45.

29. Mashhadi R, Pourmand G, Kosari F, Mehrsai A, Salem S, Pourmand MR, Alatab S, Khonsari M, Heydari F, Beladi L, Alizadeh F. Role of steroid hormone receptors in formation and progression of bladder carcinoma: a case-controi study, Urol J 2014; 11:1968-73.

30. Nam JK, Park SW, Lee SD, Chung MK. Prognostic value of sex-hormone receptor expression in non-muscle-invasive bladder cancer, Yonsei Med J. 201.55:1214-21.

31. Williams EM, Higgins JP, Sangoi AR, McKenney UK, Troxell MP. Androgen receptor immunohistochemistry in genitourinary neoplasins, Int Urol Naphirol. 2015;47:81-5.

32. Miyamoto H, Yang Z, Chen YT Chang C, et alPromotion of bladder cancer development and progression by androgen receptor signals, J Natl Cancer Inst. 2007;99:558-68.

33. Shiota M, Kiyoshima K, Yokcmizo A, et â Suppressed recurrent bladder cancer after androgen suppression with androgen deprivation therapy or $5 a-$-reductase inhibitor. $\mathrm{J}$ Urol 2017; 197(2):308-313.

34. Lin C, Yanig L, Tanasa B, er al. Nuclear receptor-induced chromosomal proximity and DNA breaks ب̂nderlie speciniétranslocations in cancer. Cell 2009;139:1069-83.

35. Mani RS, Tomlins SA, Callahan K, et al. Induced chromosomal proximity and gene fusions in prostate cancer. Science 2009; 326: 1230.

36. Izumi K, Zheng $\mathrm{Y}$, Hsu JW, et al. Androgen receptor signals regulate UDPglucuronosyltransferases in the urinary bladder: a potential mechanism of androgeninduced bladder carcinogenesis. Mol Carcinog 2013; 52: 94-102.

37. Shiota M, Takeuchi A, Yokomizo A, et al. Androgen receptor signaling regulates cell growth and vulnerability to doxorubicin in bladder cancer. J Urol 2012;188:276-86. 


\section{Page 14 of 20}

2

3

4

5

6

7

8

9

10

11

12

13

14

15

16

17

18

19

20

21

22

23

24

25

26

27

28

29

30

31

32

33

34

35

36

37

38

39

40

41

42

43

44

45

46

47

48

49

50

51

52

53

54

55

38. Overdevest JB, Knubel KH, Duex JE, et al. CD24 expression is important in male urothelial tumorigenesis and metastasis in mice and is androgen regulated. Proc Natl Acad Sci U S A 2012; 109: E3588. 
Page 15 of 20

\section{Figure Legends}

2

3 4 5 6 7

Figure 1: Pathological data (tumour staging and grading) of patients groups at $1^{\text {st }}$ TURB

Figure 2: Pathological data (tumour staging and grading) of patients groups at recurrence time, men number of relapsing patients and recurrences

Figure 3: The Kaplan-Meier curves of recurrence-free survival rates of patients treated and untreated with 5-ARIs 
Page 16 of 20

1

\begin{tabular}{|c|c|c|c|}
\hline & GROUP A & GROUP B & P VALUE \\
\hline No. of patients & 165 & 147 & \\
\hline Mean age, years (SD) & $75.23(10.51)$ & $75.12(9.27)$ & 0.93 \\
\hline \multicolumn{4}{|l|}{ Smoking status, no. (\%) } \\
\hline Never & $59(36)$ & $47(32)$ & \multirow{3}{*}{$\geq 0.05$} \\
\hline Former & $53(32)$ & $44(30)$ & \\
\hline Current & $53(32)$ & $56(38)$ & \\
\hline Follow-Up, months (SD) & $31.37(9.22)$ & $29.5(9.7)$ & 0.15 \\
\hline \multicolumn{4}{|l|}{ At $1^{\text {st }}$ TURB } \\
\hline Mean n. of lesions at $1^{\text {st }}$ TURB (SD) & $1.7(1.44)$ & $1.92(1.68)$ & 0.323 \\
\hline \multicolumn{4}{|l|}{ T stage no. $(\%)$} \\
\hline Pta & $66(40)$ & $51(35)$ & \multirow{3}{*}{$\geq 0.05$} \\
\hline Pt1 & $86(52.2)$ & $79(53.7)$ & \\
\hline$\geq \mathrm{Pt} 2$ & $13(7.8)$ & $17(113)$ & \\
\hline \multicolumn{4}{|l|}{ Grade, n. (\%) } \\
\hline Low & $56(34)$ & $36(24.8)$ & \multirow[t]{2}{*}{$\geq 0.05$} \\
\hline High & $109(65)$ & $111(752)$ & \\
\hline Carcinoma in situ, no. (\%) & $14(87)$ & $15(103)$ & 0.083 \\
\hline Relapsing patients, no. (\%) & $23(14)$ & $54(37)$ & 0.003 \\
\hline Mean no. of recurrences (SD) & $1.23(0.21)$ & $1.94(0.14)$ & 0.006 \\
\hline Mean no. of lesions at recurrence (SD) & $1.13\left(1.3 \mathrm{~s}^{\circ}\right)$ & $1.3(1.49)$ & 0.750 \\
\hline \multicolumn{4}{|l|}{ T stage, no. $(\%)$} \\
\hline Pta & $8(3.5 .3)$ & $18(33.3)$ & 0.072 \\
\hline Pt1 & $13(57)$ & $27(50)$ & 0.64 \\
\hline$\geq$ Pt2 & $2(7.7)$ & $9(16.7)$ & 0.041 \\
\hline \multicolumn{4}{|l|}{ Grade, no. (\%) } \\
\hline Low & $11(47)$ & $19(35)$ & 0.043 \\
\hline High & $12(53)$ & $35(65)$ & 0.039 \\
\hline no. of radical cystectony $(\%)$ & $13(7.8)$ & $26(17.5)$ & 0.032 \\
\hline
\end{tabular}

Table 1 Chinical and pat'nological patients' characteristics 
Page 17 of 20

Table 2: Univariate and multivariate analysis about risk of bladder cancer recurrence related to 5ARIs treatment.

\begin{tabular}{|c|c|c|c|c|}
\hline & \multicolumn{2}{|c|}{ UNIVARIATE ANALYSIS } & \multicolumn{2}{|c|}{ MULTIVARIATE ANALYSIS } \\
\hline & SHR $(95 \% \mathrm{Cl})$ & $\begin{array}{c}p \\
\text { value }\end{array}$ & SHR $(95 \% \mathrm{Cl})$ & p value \\
\hline Treatment with 5ARIs (yes - no) & $0.64(0.58-0.87)$ & 0.006 & $0.67(0.52-0.85)$ & 0.009 \\
\hline Mean age, years & $0.98(0.78-1.14)$ & 0.072 & $0.89(0.67-1.03)$ & 0.122 \\
\hline Smoking status (Never, Former, Current) & $0.87(0.64-1.04)$ & 0.068 & $0.74(0.51-1.07)$ & 0.268 \\
\hline \multicolumn{5}{|l|}{ At $1^{\text {st }}$ TURB } \\
\hline Mean $n$. of lesions at $1^{\text {st }}$ TURB & $1.07(0.84-1.24)$ & 0.082 & $1.18(0.78-1.31)$ & 0.133 \\
\hline T stage (pTa, pT1, $\geq$ Pt2) & $0.96(0.77-1.14)$ & 0.062 & $0.76(0.58-1.11)$ & 0.117 \\
\hline Grade, (Low, High) & $0.82(0.63-0.99)$ & 0.102 & $0.79(0.61-1.03)$ & 0.243 \\
\hline Carcinoma in situ (yes - no) & $0.73(0.53-1.09)$ & 0.334 & $0.75(0.43-.16)$ & 0.392 \\
\hline MMC & $0.92(0.77-1.11)$ & 0.207 & $1.02(0.72-1.23)$ & 0.315 \\
\hline BCG & $0.78(0.61-0.89)$ & 0.076 & $0.63(0.41-0.97)$ & 0.184 \\
\hline
\end{tabular}

SHR: subdistribution hazard ratio; Cl: confidence interval;:MMC: Mitornycine C; BCG: Bacillus Calmette-Guérin. 
Page 18 of 20

1
2
3
4
5
6
7
8
9
10
11
12
13
14
15
16
17
18
19
20
21
22
23
24
25
26
27
28
29
30
31
32
33
34
35
36
37
38
39
40
41
42
43
44
45
46
47
48
49
50
51
52
53
54
55

\section{At $1^{\circ}$ TURB}

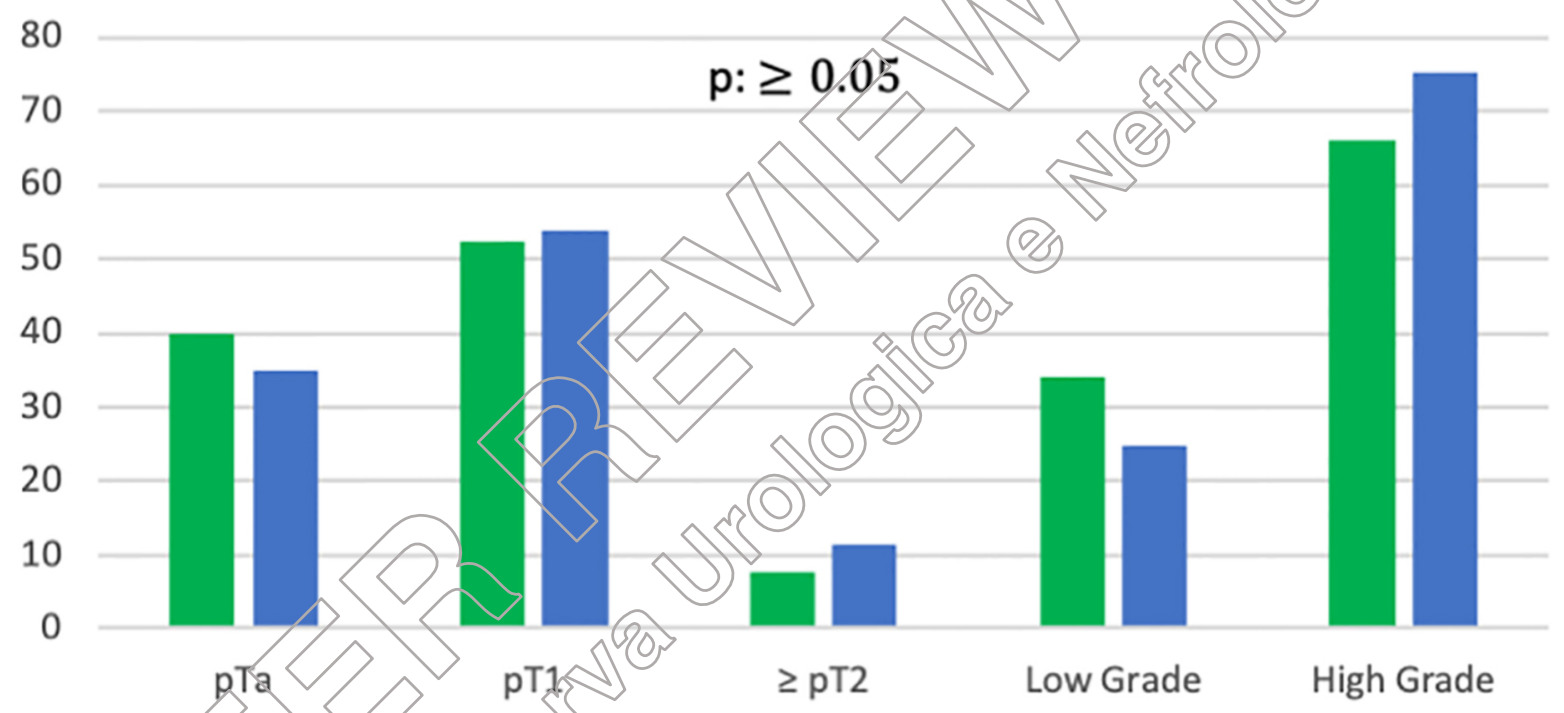

- Group A aroup B 
Page 19 of 20

1
2
3
4
5
6
7
8
9
10
11
12
13
14
15
16
17
18
19
20
21
22
23
24
25
26
27
28
29
30
31
32
33
34
35
36
37
38
39
40
41
42
43
44
45
46
47
48
49
50
51
52
53
54
55

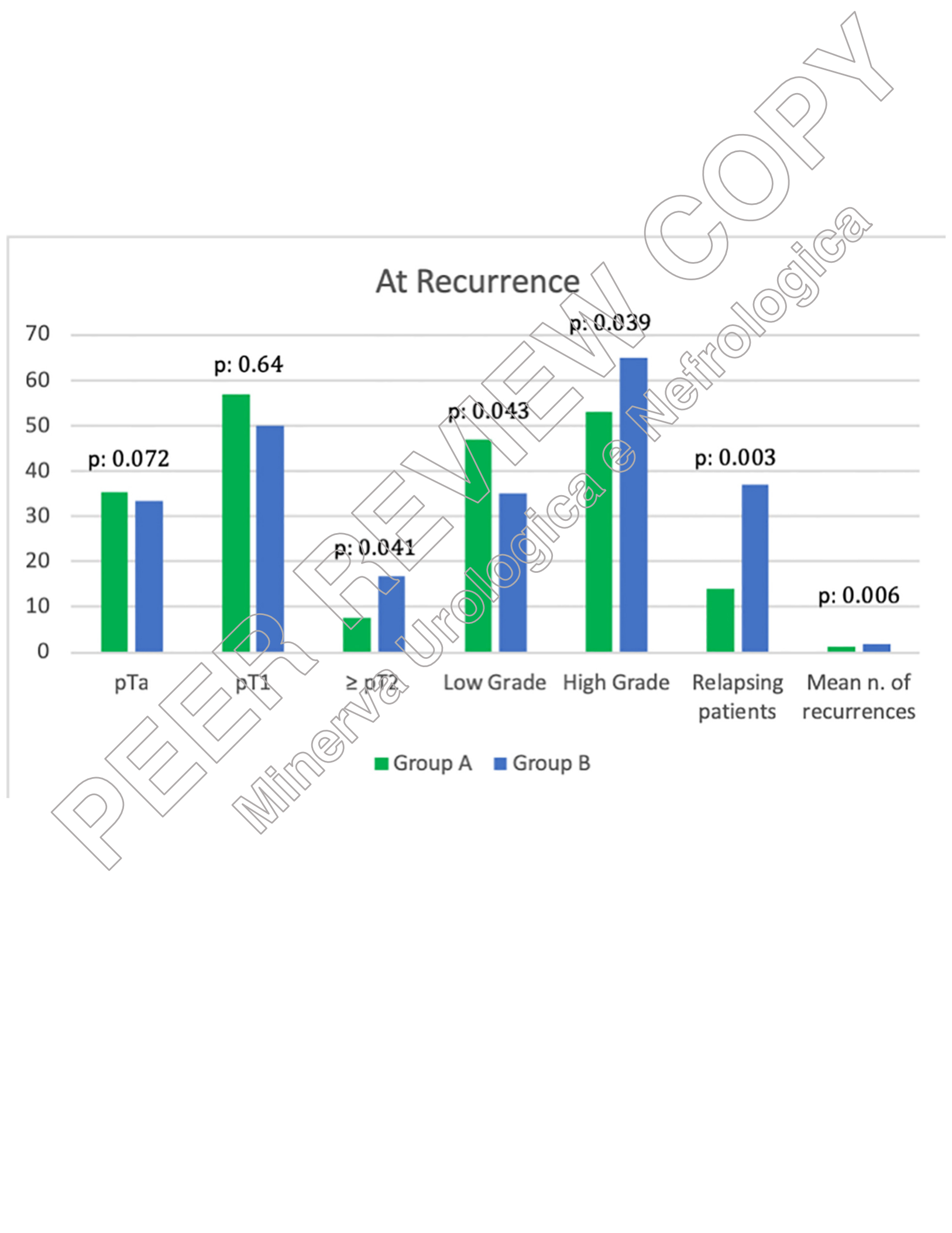


Page 20 of 20

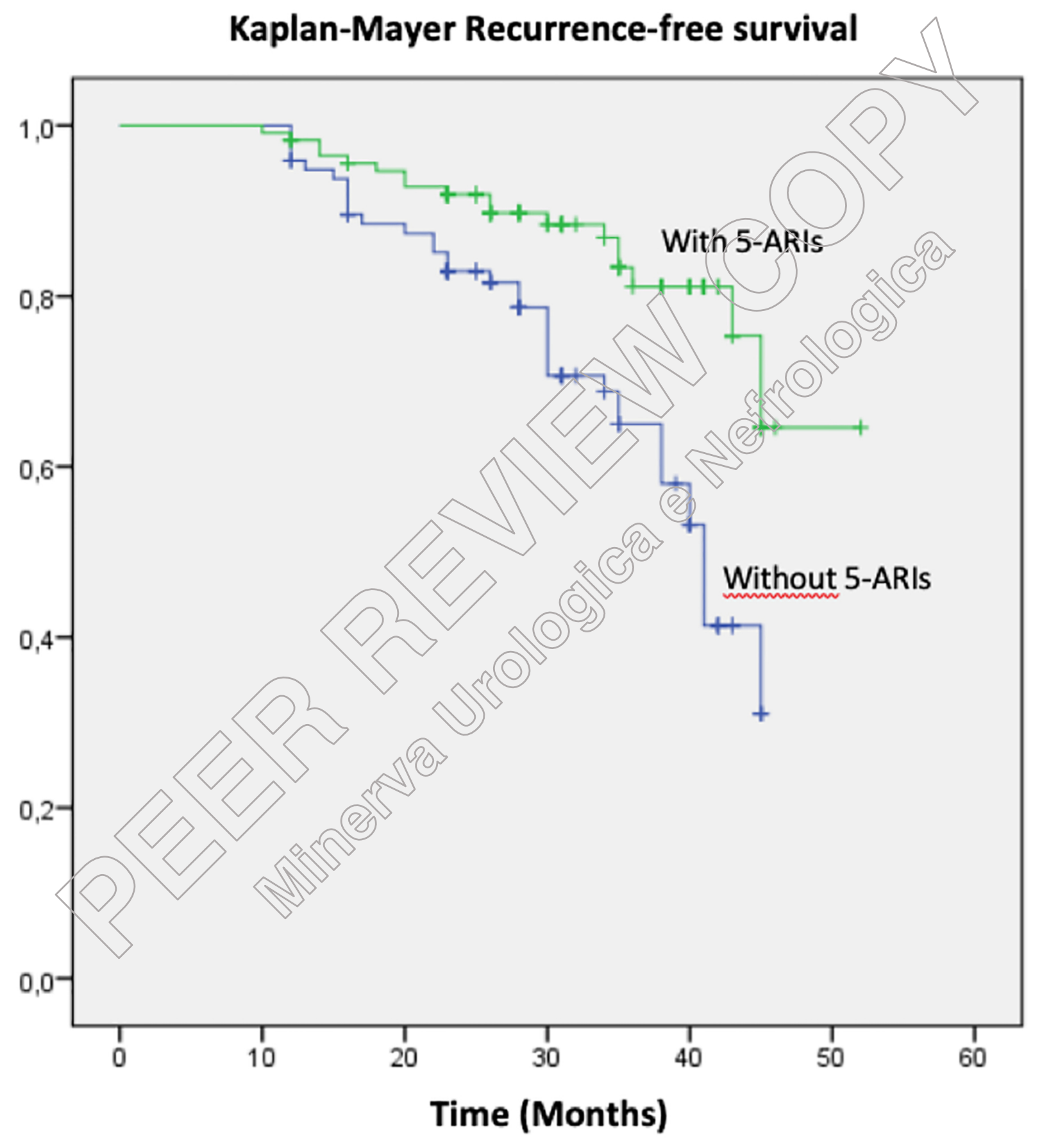

